\title{
Clinical characteristics and treatment response of chronic spontaneous urticaria according to age: A single-center Korean study
}

\author{
Yoon Hee Jo, ${ }^{1}$ Hye Won Yoo, ${ }^{1}$ Seong Heon Kim, ${ }^{2}$ Young Mi Kim, ${ }^{1}$ Hye-Young Kim ${ }^{1}$
}

\begin{abstract}
Background: Little information exists regarding the incidence of chronic spontaneous urticaria (CSU) or differences in its characteristics according to age.

Objective: To evaluate the incidence, clinical characteristics and treatment response of CSU according to age.

Methods: The relevance of gender, age, history of allergic disease, pre-diagnosis duration, and treatment response were retrospectively evaluated in patients diagnosed with CSU at Pusan National University Hospital between 2011 and 2018.

Results: A total of 970 patients were included in the study, consisting of 198 children and 772 adults. The CSU incidence increased during the study period in children, but not in adults. CSU was more common in adults than in children and the peak age of occurrence was 20-59 years. Increased female incidence was noted in adults, whereas patient and family allergic history was frequently observed in children than in adults. The overall rate of improvement was remarkably higher in children than in adults $(P<0.01)$, with pre-diagnosis duration and treatment duration both shorter in children than in adults. $(P=0.001)$. The proportion of men was higher and treatment duration was shorter in adolescence than in the other age groups, whereas the treatment duration was shorter in patients greater or equal to 60 years than in adults under 60 years, and the step 1 treatment rate was higher.
\end{abstract}

Conclusion: CSU incidence increased annually in children, but not in adults. The clinical characteristics and treatment response of CSU may differ depending on age and clinicians should be made aware of this fact.

Key words: chronic urticaria, chronic spontaneous urticaria, prevalence, prognosis, children, age

\section{Citation:}

Jo, Y. H., Yoo, H. W., Kim, S. H., Kim, Y. M., Kim, H-Y. (2022).

Clinical characteristics and treatment response of chronic spontaneous urticaria according to age: A single-center Korean study. Asian Pac J Allergy Immunol, 40(4), 374-378.

https://doi.org/10.12932/ap-050719-0594

\footnotetext{
Affiliations:

${ }^{1}$ Department of Pediatrics, Medical Research Institute,

Pusan National University School of Medicine,

Pusan National University Hospital, Busan, Republic of Korea

Department of Pediatrics, Research Institute for Convergence of Biomedical Science and Technology, Pusan National University Children's Hospital, Yangsan, Republic of Korea
}

Corresponding author:

Hye-Young Kim

Department of Pediatrics, Pusan National University Hospital,

179 Gudeok-ro, Seo-gu, Busan 602-739, Republic of Korea

E-mail: pearlhy@naver.com

\section{Introduction}

Chronic urticaria $(\mathrm{CU})$ is defined by the presence of recurrent urticaria, angioedema, or both, for a period of six weeks or longer. ${ }^{1-3} \mathrm{CU}$ is classified as either chronic spontaneous urticaria (CSU) or chronic inducible urticaria (CIU) depending on whether symptoms occur spontaneously or are induced by specific triggers. ${ }^{4}$ The prevalence of $\mathrm{CU}$ in the general population is $0.5-5 \%,{ }^{1,5,6}$ with a previous Korean study reporting that its prevalence was approximately 2,256.5 per 100,000 person-years and showed an increasing trend every year between 2010 and 2014. ${ }^{7}$ However, the epidemiology of CSU remains unclear, especially in Asian populations.

Although CSU affects all age groups, the clinical features of CSU differ according to age. CSU is generally thought to be less common in children than in adults. ${ }^{8}$ Several studies have reported no sex difference in children, whereas in adults, CSU was found to be twice as frequent in female patients. ${ }^{9-12}$ 
However, the age-related differences in CSU characteristics are not yet fully understood. Many CSU studies have focused on adults, thus there is little information on CSU prevalence or differences in its presentation according to age. Furthermore, the majority of the recommendations made in the current guidelines for the prevention and treatment of CSU in children are based on extrapolation of the data obtained from adults. ${ }^{3,8,13-15}$

Therefore, it is necessary to understand the prevalence, differences in clinical features, and treatment responses of CSU according to age. We analyzed the incidence of patients diagnosed with CSU in our hospital for 8 years and aimed to determine the clinical characteristics and treatment response of CSU according to age.

\section{Methods}

A retrospective chart review was performed on patients with CSU at Pusan National University Hospital, Busan, Korea from January 2011 to December 2018. Our university hospital is a reference center for 6 million inhabitants in Busan and Gyeongnam. Patients were first selected using the disease codes for urticaria, chronic urticaria, chronic spontaneous urticaria, chronic idiopathic urticaria, allergic urticaria, and anaphylaxis based on the International Statistical Classification of Diseases, $10^{\text {th }}$ Revision (ICD-10). Their medical records were analyzed so that only patients fulfilling the CSU diagnosis criteria were included. CSU was diagnosed according to the following criteria: the occurrence of pruritic wheals or angioedema continuously or intermittently present for at least 6 weeks when no apparent trigger or other cause is proven. Information on sex, age, history of allergic disease, family history of allergic disease, pre-diagnosis duration (duration of symptoms at the first visit), and clinical symptoms of 970 patients were collected. Of these, we analyzed 688 patients who underwent regular follow ups to assess the treatment steps, treatment duration, and improvement. Improvement was defined as no urticarial lesion for more than 3 days per week with total urticaria activity score (UAS) three or less by taking a standard dose or less of an antihistamine without other medication. ${ }^{16}$

Subjects under 20 years of age were defined as children, and those above or equal to 20 years of age were defined as adults. All patients were further classified into the following six age groups: $\leq 5,6-11,12-19,20-39,40-59$, and $\geq 60$ years. Patients were treated by evidence-based guidelines such as the EAACI/GA2LEN/EDF/WAO international guidelines and Joint Task Force on Practice Parameter. ${ }^{1,17}$ Details of the treatment steps are as follows: Step 1, second-generation H1-antihistamine at the standard dose for the age; Step 2 , increased dose or combination with first-generation antihistamine and leukotriene receptor antagonist; Step 3, adjuvant agents including omalizumab, cyclosporine, immunosuppressants, or other anti-inflammatory agents. This study was approved by the Pusan National University Hospital Institutional Review Board for human subjects and experimental animals (PNUHIRB 1904-020-078).
Statistical analyses were performed using IBM SPSS ver. 20.0 and the Chi-square test and Fisher's exact test were used to the test the statistical significance of differences between children and adults. Kaplan-Meier curves were used to assess the improvement rate of children and adults, which were analyzed by log-rank tests. Data were considered to be statistically significant if the $p$-value was $<0.05$.

\section{Results}

A total of 970 patients were included in the study, consisting of 198 children and 772 adults. The mean age at diagnosis was $8.4 \pm 5.1$ years for children and $43.1 \pm 14.6$ years for adults (Table 1). Eighty-three (42.0\%) children and $464(60.1 \%)$ adults were female, with the proportion of females significantly higher in adults than in children $(P=0.009)$. Among the patients, $11.1 \%$ of the children and $10.4 \%$ of the adults were found to have angioedema and anaphylaxis associated with urticaria. There was a history of allergic disease in $15.7 \%$ of the children and $7.1 \%$ of the adults, whilst a family history of allergic disease was found in $16.2 \%$ of the children and $2.6 \%$ of the adults. The allergic history of patients and their family was significantly higher in children than in adults (Table 1).

Table 1. Demographic characteristics of patients

\begin{tabular}{|l|c|c|c|}
\hline Characteristic & $\begin{array}{c}\text { Children } \\
(\mathbf{n}=\mathbf{1 9 8})\end{array}$ & $\begin{array}{c}\text { Adults } \\
(\mathbf{n}=772)\end{array}$ & P-value \\
\hline Age at initial diagnosis (years) & $8.4 \pm 5.1$ & $43.1 \pm 14.6$ & \\
Sex, N (\%) & $115(58.0)$ & $308(39.9)$ & $0.009^{*}$ \\
Male & $83(42.0)$ & $464(60.1)$ & \\
Female & $22(11.1)$ & $80(10.4)$ & 0.298 \\
Associated symptoms, N (\%) & $21(10.6)$ & $71(9.2)$ & \\
angioedema & $4(2.0)$ & $20(2.6)$ & \\
anaphylaxis & $31(15.7)$ & $55(7.1)$ & $0.022^{*}$ \\
History of allergic disease, N (\%) & $21(10.6)$ & $4(0.5)$ & \\
Atopic dermatitis & $29(14.6)$ & $39(5.1)$ & \\
Allergy rhinitis & $7(3.5)$ & $1(0.1)$ & \\
Food allergy & $4(2.0)$ & $12(1.6)$ & \\
Asthma & $4(2.0)$ & $9(1.2)$ & \\
Drum allergy & $20(2.6)$ & \\
\hline
\end{tabular}

Values represent the mean \pm standard deviation; $N$, number (\%). ${ }^{\star} P<0.05$ was considered statistically significant. 
The incidence of CSU in children increased annually during the study period, whereas the incidence of CSU in adults was variable (Figure 1). The incidence of CSU in children increased rapidly from 73 per 100,000 patients who visited at Pusan National University Hospital in 2011 to 76.1 in 2012, 90.2 in 2013, 98.1 in 2014, 112.3 in 2015, 149 in 2016, 176.9 in 2017, and 187 in 2018. In adults, the greatest number of patients were diagnosed in 2013 (173.2 per 100,000 patients) and the smallest number of patients were diagnosed in 2016 (108.8 per 100,000 patients).
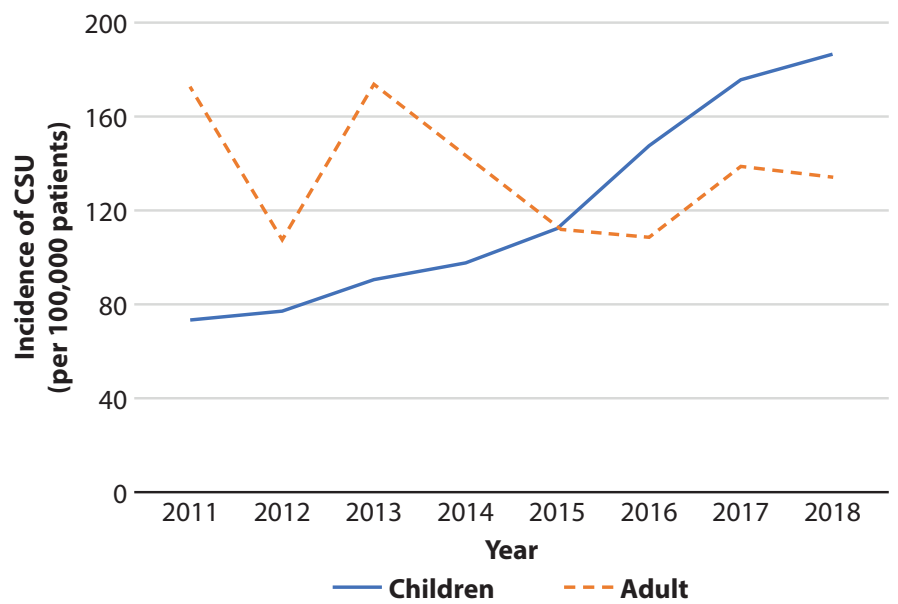

Figure 1. Incidence of chronic spontaneous urticaria in children and adults from Pusan National University Hospital between 2011 and 2018

Of the 970 patients, 688 (126 children and 562 adults) were monitored regularly in our hospital. The pre-diagnosis duration (mean $\pm \mathrm{SD}$ ) was $6.9 \pm 11.2$ months in children and $14.2 \pm 27.9$ months in adults (Table 2); thus, it was significantly shorter in children than in adults $(P=0.001)$. Step 1 treatment was performed in $73.8 \%$ of the children and $63.3 \%$ of the adults, whereas step 2 or 3 treatments were performed in $26.2 \%$ of the children and $36.7 \%$ of the adults. The treatment duration (mean \pm SD) was $9.2 \pm 13.0$ months in children and $13.3 \pm 18.8$ months in adults; therefore, children had a significantly shorter treatment duration than adults $(P=$ 0.011 ). The duration of step 1 treatment (mean \pm SD) was 6.6 \pm 9.3 months in children, and $10.6 \pm 15.6$ months in adults; thus, it was significantly shorter in children than in adults $(P$ $=0.001$ ). The duration of step 2 or 3 treatments (mean \pm SD) was $16.5 \pm 18.4$ months in children and $18.0 \pm 22.5$ months in adults; however, there was no significant difference between the two groups (Table 2).

Improvements were observed in 113 (89.7\%) of 126 children and 435 (77.4\%) of 562 adults after treatment. Kaplan-Meier survival analysis revealed that the improvement rates 6,12 , and 24 months after treatment were 60.6, 77.8, and $89.2 \%$ in children and $45.7,63.2$, and $74.6 \%$ in adults, respectively (Figure 2), demonstrating a significantly higher CSU improvement rate in the children than in the adults $(P<0.001)$.
Table 2. Treatment response of patients

\begin{tabular}{|l|c|c|c|} 
& $\begin{array}{c}\text { Children } \\
(\mathbf{n}=\mathbf{1 2 6})\end{array}$ & $\begin{array}{c}\text { Adult } \\
(\mathbf{n}=\mathbf{5 6 2})\end{array}$ & P-value \\
\hline $\begin{array}{l}\text { Pre-diagnosis duration } \\
\text { (months) }\end{array}$ & $6.9 \pm 11.2$ & $14.2 \pm 27.9$ & $0.001^{*}$ \\
Treatment steps, N (\%) & $93(73.8)$ & $356(63.3)$ & 0.0781 \\
Step 1 & $33(26.2)$ & $206(36.7)$ & \\
Step 2 or 3 & $9.2 \pm 13.0$ & $13.3 \pm 18.8$ & $0.011^{*}$ \\
Treatment duration (months) & $6.6 \pm 9.3$ & $10.6 \pm 15.6$ & $0.001^{*}$ \\
Step 1 & $16.5 \pm 18.4$ & $18.0 \pm 22.5$ & 0.061 \\
\hline
\end{tabular}

Values represent the mean \pm standard deviation; N, number (\%). ${ }^{\star} P<0.05$ was considered statistically significant

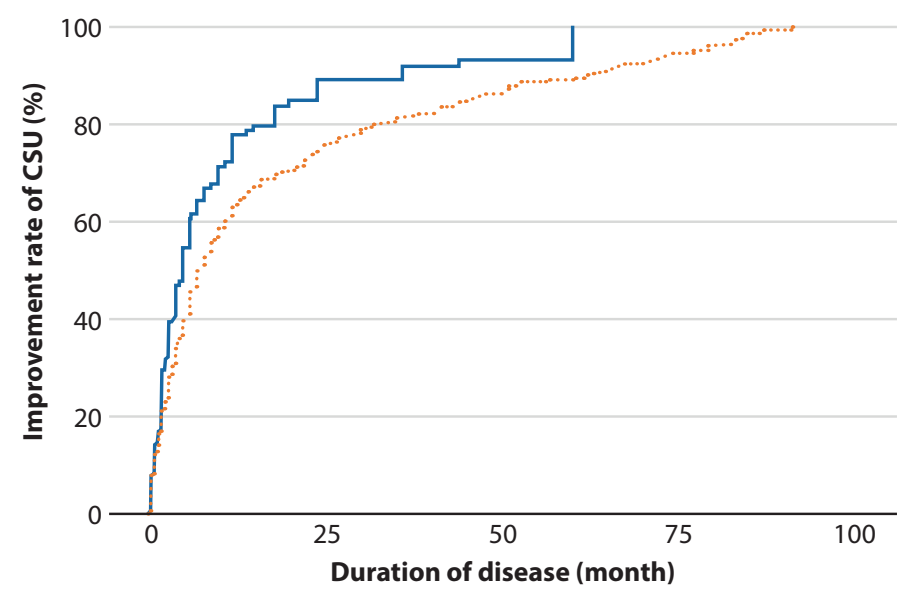

Figure 2. Kaplan-Meier analysis of children (solid line) and adults (dashed line) with chronic spontaneous urticaria $(P<0.001)$

The clinical characteristics of CSU according to age are shown in Table 3. Among 688 patients, the age distribution was as follows: $53(7.7 \%)$ aged $\leq 5,36(5.2 \%)$ aged $6-11,37$ (5.4\%) aged 12-19, $244(35.5 \%)$ aged 20-39, 239 (34.7\%) aged 40-59, 79 (11.5\%) aged $\geq 60$. Those aged 20-59 accounted for the largest number of patients (70.2\%). In adults, the female sex ratio was higher, especially for patients over the age of 40 . In adolescents, the proportion of males was higher (67.6\%) and pre-diagnosis duration and treatment duration was shorter than in the other groups. Patients greater than or equal to the age of 60 had a longer pre-diagnosis duration; however, their treatment duration was shorter than the other adult groups. Patients below or equal to the age of 5 had a high rate of step 1 treatment, whilst patients aged 40-59 had a higher rate of step 2 or 3 treatments. 
Table 3. Clinical characteristics of chronic spontaneous urticaria according to the age groups

\begin{tabular}{|c|c|c|c|c|c|c|}
\hline \multirow{2}{*}{ Age (years) } & \multicolumn{3}{|c|}{ Children $(n=126)$} & \multicolumn{3}{|c|}{ Adults $(n=562)$} \\
\hline & $\leq 5$ & 6-11 & 12-19 & 20-39 & 40-59 & $\geq 60$ \\
\hline Number (\%) & $53(7.7)$ & $36(5.2)$ & $37(5.4)$ & $244(35.5)$ & $239(34.7)$ & $79(11.5)$ \\
\hline \multicolumn{7}{|l|}{ Sex } \\
\hline Male & $26(49.1)$ & $16(44.4)$ & $25(67.6)$ & $111(45.5)$ & $86(36.0)$ & $28(35.4)$ \\
\hline Female & $27(50.9)$ & $20(55.6)$ & $12(32.4)$ & $133(54.5)$ & $153(64.0)$ & $51(64.6)$ \\
\hline Pre-diagnosis duration (months) & $6.3 \pm 9.5$ & $9.6 \pm 14.2$ & $5.2 \pm 9.8$ & $11.2 \pm 19.3$ & $16.2 \pm 32.1$ & $17.3 \pm 35.4$ \\
\hline Treatment duration (months) & $8.8 \pm 11.8$ & $11.0 \pm 16.0$ & $7.9 \pm 11.4$ & $14.0 \pm 19.4$ & $13.2 \pm 18.3$ & $11.7 \pm 18.3$ \\
\hline \multicolumn{7}{|l|}{ Treatment step } \\
\hline Step 1 & $42(79.2)$ & $25(69.4)$ & $26(70.3)$ & $160(65.6)$ & $138(57.7)$ & $58(73.4)$ \\
\hline Step 2 or 3 & $11(20.8)$ & $11(30.6)$ & $11(29.7)$ & $84(34.4)$ & $101(42.3)$ & $21(26.6)$ \\
\hline
\end{tabular}

Values represent the mean \pm standard deviation, $\mathrm{N}$, number (\%).

\section{Discussion}

Our study confirmed differences in the incidence, clinical characteristics, and treatment response of CSU according to age. We found that the incidence of CSU in children increased rapidly over the last 8 years from 73 per 100,000 patients in 2011 to 187 per 100,000 patients in 2018; however, the incidence in adults did not increase. CU is considered less prevalent in children than in adults, with its prevalence in Korean children estimated at $1.8 \%{ }^{3}$ Recent nationwide Korean data reported that the annual prevalence of $\mathrm{CU}$ consistently increased from $1,662.3$ per 100,000 people in 2010 to $2,301.8$ per 100,000 people in $2014 ;^{7}$ however, they did not investigate the change in annual CU prevalence by age. The reason for the rapid increase in pediatric CSU incidence observed in our study remains unclear; therefore, further continuous large-scale studies are required to investigate the change in CSU incidence by age, with a particular focus on CSU incidence in children.

This study showed that CSU is more common in adults than in children and that the peak age of incidence was 2059 years old. A female bias was also noted in adults, in close agreement with several other studies. This gender difference is presumed to be due to the effects of sex hormone and autoimmunity. ${ }^{18-22}$ Although there are conflicting hypotheses about the correlation between CSU and allergic disease, several studies have proposed a strong link between CSU and allergic disease in children. ${ }^{23-25}$ Our study also found that the allergic history of patients and their families was significantly more frequent in children than in adults.

The natural course of CSU is not yet fully understood. Spontaneous remission generally occurs in $30-50 \%$ of patients within a year and the average disease duration is known to be $2-5$ years. ${ }^{13}$ However, the reported remission rates at 12 and 60 months $(16.5-84.8 \%$ and $50-67.5 \%$ in children and $11.5-35 \%$ and $27.7-86 \%$ in adults) are highly variable. . $^{8,16,18,26-32}$ This can be explained by differences in the characteristics of the study population examined herein, including race, CSU inclusion criteria, treatment methodology, the definition of remission or improvement, and study methods.
In our study, the improvement rates 6,12 , and 24 months after treatment were $60.6,77.8$, and $89.2 \%$ in children and $45.7,63.2$, and $74.6 \%$ in adults, respectively. Notably, the overall improvement rate of the children was significantly higher than that of the adults. We also found that treatment duration, specifically step 1 treatment duration, was significantly shorter in children than in adults, whilst patients aged 40-59 had a higher rate of step 2 or 3 treatment than any other group. These results suggest that CSU in children has better prognosis than in adults, consistent with a Japanese study which reported that the remission rates of CSU in children were significantly higher than in adults. ${ }^{16}$

Interestingly, this study demonstrated differences in the clinical features of CSU by age, especially in adolescents and the elderly. In adolescents, the proportion of males was higher and treatment duration was shorter than that in the other groups, whereas in patients aged $\geq 60$ years, the treatment duration was shorter and the step 1 treatment rate was higher. An American study reported differences in the baseline clinical characteristics of adults and adolescents with CSU and showed that adolescents tended not to have experienced CSU for as long as adults $\operatorname{did} .{ }^{33}$ A Thai study showed that aging patients with $\mathrm{CU}$ seemed to have a shorter disease duration ${ }^{34}$ however, studies focusing on the clinical features of $\mathrm{CU}$ in adolescents or the elderly are limited, necessitating further research.

There are several limitations to this study. Firstly, data were obtained from only one center specialized in treating allergies and the patients may have exhibited more severe symptoms than those in general hospitals or clinics. Secondly, since this was a retrospective study, selection bias may have been introduced. However, our findings suggesting differences in the incidence, clinical characteristics, and treatment response of CSU by age are encouraging, improve our understanding of CSU by age, and could be helpful for clinicians. 


\section{Conflicts of Interest}

The authors have no potential conflicts of interest to declare with respect to the authorship and/or publication of this article.

\section{Source of Funding with grant numbers} None

\section{Author Contributions}

- YHJ, HWY, SHK, YMK and HYK participated in the design of the study and conducted the study.

- YHJ and HYK drafted the manuscript and performed the statistical analysis of the study.

- All of the authors read and approved the final manuscript.

\section{References}

1. Bernstein JA, Lang DM, Khan DA, Craig T, Dreyfus D, Hsieh F, et al. The diagnosis and management of acute and chronic urticaria: 2014 update. J Allergy Clin Immunol. 2014;133(5):1270-7. e66.

2. Brüske I, Standl M, Weidinger S, Klümper C, Hoffmann B, Schaaf $B$, et al. Epidemiology of urticaria in infants and young children in Germany-Results from the German LISA plus and GINI plus Birth Cohort Studies. Pediatr Allergy Immunol. 2014;25(1):36-42.

3. Lee SJ, Ha EK, Jee HM, Lee KS, Lee SW, Kim M, et al. Prevalence and risk factors of urticaria with a focus on chronic urticaria in children. Allergy Asthma Immunol Res. 2017;9(3):212-9.

4. Park H, Lee JY, Song A, Jung M, Kim M, Sohn I, et al. Natural course and prognostic factors of chronic urticaria in Korean children: A single center experience. Asian Pac J Allergy Immunol. 2019;37(1):19-24.

5. Kanchanapoomi K, Pacharn P, Visitsunthorn N, Jirapongsananuruk O. Medication used to control symptoms of chronic urticaria in children. Asian Pac J Allergy Immunol. [Preprint]. 2018[cited 2019 Jun 20]. Available from: http://apjai-journal.org/wp-content/uploads/2018/12/ AP-010218-0247.pdf.

6. Quirt J, Lima H, Waserman S. Urticaria: a Multidisciplinary Disease. Where Are We Now? Curr Derm Rep. 2015;4(1):8-14

7. Lee N, Lee J-D, Lee H-Y, Kang DR, Ye Y-M. Epidemiology of chronic urticaria in Korea using the Korean Health Insurance Database, 2010-2014. Allergy Asthma Immunol Res. 2017;9(5):438-45.

8. Sahiner UM, Civelek E, Tuncer A, Yavuz ST, Karabulut E, Sackesen C, et al. Chronic urticaria: etiology and natural course in children. Int Arch Allergy Immunol. 2011;156(2):224-30.

9. Caffarelli C, Cuomo B, Cardinale F, Barberi S, Dascola CP, Agostinis F, et al. Aetiological factors associated with chronic urticaria in children: a systematic review. Acta Derm Venereol. 2013;93(3):268-72.

10. Choi SH, Baek HS. Approaches to the diagnosis and management of chronic urticaria in children. Korean J Pediatr. 2015;58(5):159.

11. Choi SY, Park HY, Ahn YM. Chronic urticaria in childhood: etiology and outcome. Pediatr Allergy Resp Dis. 2007;17(1):38-47.

12. Jirapongsananuruk O, Pongpreuksa S, Sangacharoenkit P, Visitsunthorn $\mathrm{N}$, Vichyanond P. Identification of the etiologies of chronic urticaria in children: a prospective study of 94 patients. Pediatr Allergy Immunol. 2010;21(3):508-14.

13. Greaves M. Chronic urticaria. J Allergy Clin Immunol. 2000;105(4): 664-72.

14. Hamel-Teillac D. [Chronic urticaria in children]. Ann Dermatol Venereol. 2003;130 Spec No 1:1S69-72. French.
15. Zuberbier T, Balke M, Worm M, Edenharter G, Maurer M. Epidemiology of urticaria: a representative cross-sectional population survey. Clin Exp Dermatol: Clinical. 2010;35(8):869-73.

16. Hiragun $M$, Hiragun $T$, Mihara $S$, Akita $T$, Tanaka J, Hide $M$. Prognosis of chronic spontaneous urticaria in 117 patients not controlled by a standard dose of antihistamine. Allergy. 2013;68(2):229-35.

17. Zuberbier $\mathrm{T}$, Aberer W, Asero R, Abdul Latiff AH, Baker D, Ballmer-Weber $\mathrm{B}$, et al. The EAACI/GA ${ }^{2} \mathrm{LEN} / \mathrm{EDF} / \mathrm{WAO}$ guideline for the definition, classification, diagnosis and management of urticaria. Allergy. 2018;73(7):1393-414

18. Kim YS, Park SH, Han K, Lee JH, Kim NI, Roh JY, et al. Clinical course of chronic spontaneous urticaria in the Korean adult population. Allergy Asthma Immunol Res. 2018;10(1):83-7.

19. Lee H-C, Hong J-B, Chu C-Y. Chronic idiopathic urticaria in Taiwan: a clinical study of demographics, aggravating factors, laboratory findings, serum autoreactivity and treatment response. J Formos Med Assoc. 2011;110(3):175-82.

20. Maurer M, Weller K, Bindslev-Jensen C, Giménez-Arnau A, Bousquet $P$, Bousquet J, et al. Unmet clinical needs in chronic spontaneous urticaria. A GA2LEN task force report 1. Allergy. 2011;66(3):317-30.

21. Kasperska-Zajac A, Brzoza Z, Rogala B. Sex hormones and urticaria. J Dermatol Sci. 2008;52(2):79-86.

22. Kolkhir P, Borzova E, Grattan C, Asero R, Pogorelov D, Maurer M Autoimmune comorbidity in chronic spontaneous urticaria: a systematic review. Autoimmun Rev. 2017;16(12):1196-208.

23. Cornillier H, Giraudeau B, Munck S, Hacard F, Jonville-Bera AP d'Acremont G, et al. Chronic spontaneous urticaria in children-a systematic review on interventions and comorbidities. Pediatr Allergy Immunol. 2018;29(3):303-10.

24. Rosman Y, Hershko AY, Meir-Shafrir K, Kedem R, Lachover-Roth I, Mekori YA, et al. Characterization of chronic urticaria and associated conditions in a large population of adolescents. J Am Acad Dermatol 2019;81(1):129-35.

25. Zazzali JL, Broder MS, Chang E, Chiu MW, Hogan DJ. Cost, utilization, and patterns of medication use associated with chronic idiopathic urticaria. Ann Allergy Asthma Immunol. 2012;108(2):98-102.

26. Van Der Valk P, Moret G, Kiemeney L. The natural history of chronic urticaria and angioedema in patients visiting a tertiary referral centre. $\mathrm{Br}$ J Dermatol. 2002;146(1):110-3.

27. Toubi E, Kessel A, Avshovich N, Bamberger E, Sabo E, Nusem D, et al. Clinical and laboratory parameters in predicting chronic urticaria duration: a prospective study of 139 patients. Allergy. 2004;59(8):869-73.

28. Kulthanan K, Jiamton S, Thumpimukvatana N, Pinkaew S. Chronic idiopathic urticaria: prevalence and clinical course. J Dermatol. 2007 34(5):294-301.

29. Kozel MM, Mekkes JR, Bossuyt PM, Bos JD. Natural course of physical and chronic urticaria and angioedema in 220 patients. J Am Acad Dermatol. 2001;45(3):387-91.

30. Kang HS, Shin MY. Clinical aspects of chronic urticaria in children. Korean J Pediatr. 2009;52(2):205-12.

31. Eser I, Yologlu N, Baydemir C, Aydogan M. The predictive factors for remission of chronic spontaneous urticaria in childhood: outcome from a prospective study. Allergol Immunopathol. 2016;44(6):537-41.

32. Chansakulporn S, Pongpreuksa S, Sangacharoenkit P, Pacharn P, Visitsunthorn N, Vichyanond P, et al. The natural history of chronic urticaria in childhood: a prospective study. J Am Acad Dermatol. 2014; 71(4):663-8

33. Goldstein S, Gabriel S, Kianifard F, Ortiz B, Skoner DP. Clinical features of adolescents with chronic idiopathic or spontaneous urticaria: review of omalizumab clinical trials. Ann Allergy Asthma Immunol. 2017;118(4):500-4.

34. Chuamanochan M, Kulthanan K, Tuchinda P, Chularojanamontri L, Nuchkull P. Clinical features of chronic urticaria in aging population. Asian Pac J Allergy Immunol. 2016;34(3):201-5. 